\title{
MULTI OBJECTIVE OPTIMIZATION OF PROCESS PARAMETERS BY FIREFLY ALGORITHM DURING THE FRICTION STIR WELDING OF METAL MATRIX COMPOSITES
}

\begin{abstract}
Summary
The use of composite materials in practical applications can be further enhanced by joining them effectively. In the current research, composites of Al 5083 reinforced with 10\% $\mathrm{B}_{4} \mathrm{C}$ were prepared using the stir casting technique and were joined by friction stir welding. The process parameters, i.e. tool revolving speed, welding feed, and vertical plunge force were considered and taken in three levels to analyse their influence on mechanical properties, such as ultimate tensile strength and micro hardness. To make a joint, two tools with a square tool pin profile were machined, one coated with titanium nitride (TiN) and the other with diamond like carbon (DLC).Experiments were planned as per Box - Behenken's design which suggested 15 experiments to analyse the output response. A mathematical model was developed for each output response for both the tools and the reliability of the model was confirmed by conducting the ANOVA test. The effect of varying each parameter on output parameters was studied and compared for both tools. Multi objective optimization was done by the firefly algorithm using the MATLAB 2018a software. For the TiN coated tool, maximum tensile strength of $133.92 \mathrm{MPa}$ and Vickers micro hardness value of 102.54 were obtained with the following process parameters: $1540 \mathrm{rpm}, 20 \mathrm{~mm} / \mathrm{min}, 6 \mathrm{KN}$. As far as the DLC tool is concerned, the maximum values obtained are $129.67 \mathrm{MPa}$ and 102.47 with the following parameters: $1360 \mathrm{rpm}, 55 \mathrm{~mm} / \mathrm{min}$, and $8 \mathrm{KN}$.
\end{abstract}

Keywords: $\quad A l 5083+B_{4} C$ composites, Titanium nitride, Diamond like carbon, Box-Behenken's design, Multi objective optimization

\section{Introduction}

The rapid growth of aluminium matrix composites started after the Technology Research Corporation of United States had submitted the aluminium metal matrix composite (MMC) roadmap 2002 which signposted the progress of aluminium metal matrix composites in the next 20 years. In 2014, the Grand View Research market report projected that lightweight aluminium based metal matrix composites, due to their high tensile strength, are the largest product segment with a 30\% demand. As reported, the aluminium based material will continue to mature and will be the leader in metal matrix composites until 2022. Figure 1 shows the progress trend of various metals used for MMCs until 2022[1]. 


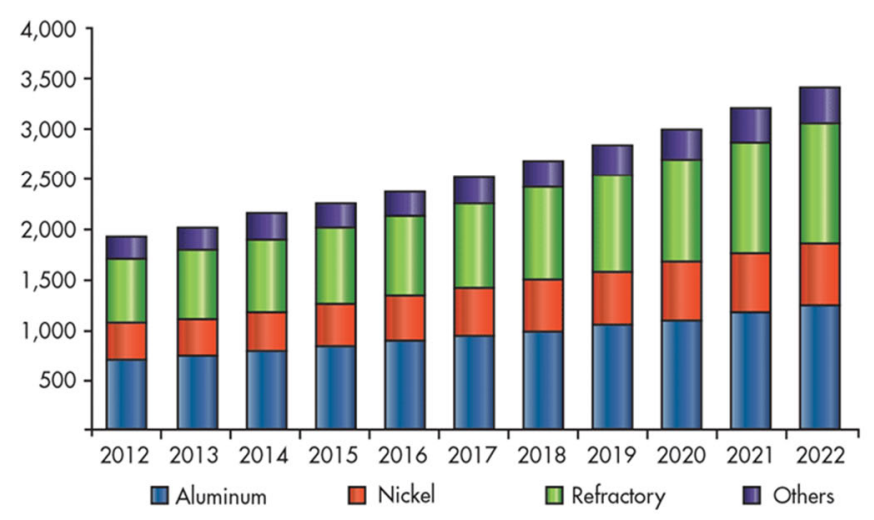

Fig. 1 Progress trend of various metals used for MMCs until 2022[1].

In the recent years, these materials have attracted full attention of diverse industrial sectors in critical applications such as aircraft structures, naval structures, components of automotive, and, air craft propulsion systems, and tank armours. Among MMCs Al 5083 $\mathrm{B}_{4} \mathrm{C}$ composite is the best candidate material for bullet proof vests, tank armours and for neutron absorbers in nuclear power plants. The Al-based MMC can be used as a good replacement for a durable material but it can also allow crucial changes to be made to the product or to the design of the entire system. However, difficulties arise in joining these materials by means of conventional joining processes, such as vacuum brazing, metal inert gas welding, gas tungsten arc welding laser welding and resistance spot welding. The application of aluminium matrix composites can be additionally increased by ensuring proper joining techniques. The main drawbacks associated with the fusion welding of composite materials are the formation of undesirable deleterious phases, excessive eutectic formation and the formation of porosity in the fusion zone.

To overcome the aforementioned problems, Wayne Thomas from The Welding Institute found a solution in 1991; he invented a new welding process, friction stir welding (FSW), in which a hard solid spinning tool with shoulder and pin was used. Due to frictional heat, the material to be joined is plasticized, and as the tool is moved, a consolidated solid -phase joint is formed. Ever since its invention, the process has been adopted in several branches of manufacturing and engineering. The aviation industry adopted the process and used it in the Boeing delta rocket fuel tank and, NASA's external fuel tank barrel [2]. Today, almost every launch vehicle manufacturer in the private or government sector uses the process in the manufacturing of various parts of vehicles.

Since joining is carried out in the solid state at temperatures well below the melting point of the parent materials, the process has a lot of advantages in terms of metallurgical and environmental aspects over the conventional fusion welding process.

The typical process is simple and it takes place in the solid state in which amalgamation of the material takes place because of the stirring action performed by the rotating tool, usually non-consumable in nature. The tool is considered as the heart of the welding process; it has two main parts, namely a shoulder and a pin, which heats the workpiece material by friction. To create a joint, the tool will be plunged into the workpiece until the bottom surface of the shoulder interacts with the top surface of the material to be joined. The tool performs three main functions: heating of the base material, stirring, and transferring the material into a plastic state; this results in the joining of the base material.

The simple process can be carried out in three phases, namely, plunge phase from which the weld originates, the main phase in which the weld is prepared, and the last, termination phase, in which the tool is retracted from the base material. The basic process is shown in Fig. 2. 


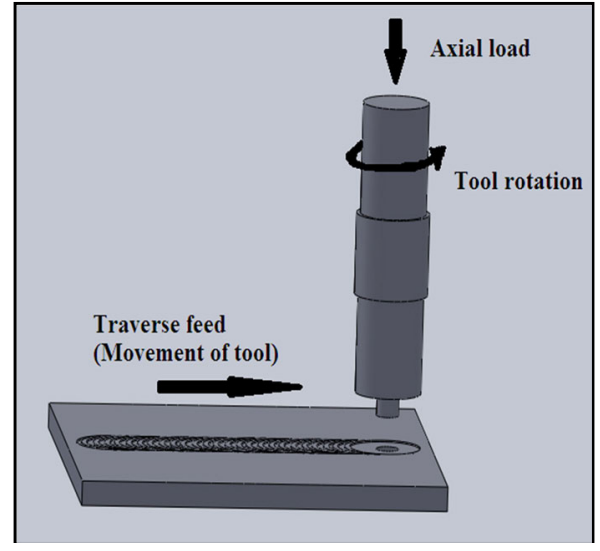

Fig. 2 The basic FSW process

An extensive literature on the friction stir welding process shows that it can be effectively employed to weld difficult to weld materials with better mechanical properties. S.Vijayan et al. [3] joined the Al 5083 alloy and did optimization using the Gray relational analysis to maximize the tensile strength of the welded joint at minimum power consumption. The published results of experiments reveal that the tool rotational speed is a highly significant factor and that an increase in the axial force consumes more power. H.Nami et al. [4] joined pure aluminium reinforced with $\mathrm{Mg} 2 \mathrm{Si}$ particles to analyse the influence of the tool rotational speed and the number of passes on the mechanical properties and microstructure of the weld. Experimental results revealed that the tensile strength increases up to a certain level of increase in rotational speed, then it decreases due to the formation of defects. The number of welding passes had an inverse effect on the tensile strength of the weld and produced defective welds.

Dinaharan et al. [5] made an attempt to weld the composite AA 6061 reinforced with $\mathrm{ZrB}_{2}$ and studied the mechanical properties and wear resistance of the weld. Mathematical models were developed and process parameters were optimized by a generalized reduced gradient method. Kalaiselvan et al. [6] studied the effect of process parameters on the tensile strength of AA 6061 reinforced with $\mathrm{B}_{4} \mathrm{C}$ materials. The process parameters were optimized using the generalized reduced gradient method.

Adel Mahmood Hassan [7] focused on the influence of various parameters such as tool pin profile, rotational speed, and welding speed on wear characteristics of the welded joint created while joining hybrid aluminium composites. The results indicated that wear resistance increases when the welding speed increases and the spindle speed decreases. Among the various profiles considered, a square pin profile had better wear resistance compared to other profiles. The same researcher also proved that the FSW process can be used to join aluminium matrix composites successfully; the mechanical properties of the joint improved while increasing the welding speed and decreasing the rotational speed.

Tracie Prater [2] studied the ways how to extend the usability of MMC in aerospace industries and to combat the tool wear. His findings showed that the best way to tackle the tool wear is to select the proper tool material; diamond coatings are a good choice for the tool material.

Mohsen Bahrami et al. [8] considered different tool pin geometries to evaluate the macrostructure, microstructure, and mechanical properties of the weld created while joining Al 7075 reinforced with nano $\mathrm{SiC}$ particles. A triangular tool pin produced the maximum tensile strength. C.Ravindiran et al. [9] made an extensive review of joining the aluminium metal matrix by friction stir welding and gave a few recommendations. The authors consider that more work need to be done to define the welding window of each composite for optimizing the properties because, as of now, there is no common relation between the 
process parameters and mechanical properties of the weld while joining different types of AMC's. V.K Parikh et al. [10] reviewed the available papers on the FSW of metal matrix composites. His meticulous review revealed that studies related to the multi objective optimization of FSW process parameters will increase the use of composites and the acceptability of the process in manufacturing industries. The tool wear, especially the pin portion of the tool, remains the key issue; to combat the tool wear, several researchers recommended the use of the coated tool and the surface - treated tool. D.Jayabalakrishnan et al. [11] studied the joining of aluminium and copper, including graphene nanoparticles as reinforcement, by using a normal and an offset tool pin and concluded that eccentric stirring with the offset tool pin had produced minimum tool wear. M. Jayaraman et al. [12] joined cast aluminium-based alloys such as A319, A 356, and A413, to study the tensile strength, hardness, and ductility of the joint by varying the process parameters. The empirical relationship was also developed to predict the mechanical properties.

Y.G. Kim et al. [13] concentrated on three types of defects formed while joining aluminium die casting alloys. The researchers found that the flash and groove like defects are formed due to an excessive or insufficient heat input, whereas the cavity like defect was formed due to abnormal stirring. D. Klobear et al. [14] used a tool without a pin to carry out the friction stir spot welding of Al 5154 alloy and to study the influence of axial force, torque, microstructure and energy input. The experiment results showed that better joint strength was obtained at a lower plunge rate, a higher rotational speed of the tool, and extended dwell times.

E.Shankar et al. [15] investigated the performance of TiAlN coating put on tungsten carbide rollers used in burnishing boron carbide reinforced metal matrix composites and found that the coating had improved the workpiece hardness after burnishing. Several researchers [16-21] carried out extensive research on joining various materials like aluminium foam, metal matrix composites, and even dissimilar materials.

The term Swarm Intelligence (SI) was first used probably by Beni in the sense of cellular robotic systems [21].The firefly algorithm has gradually become a significant tool of swarm intelligence that has been applied in virtually all areas of optimization. Yang et al. [22] implemented the Firefly Algorithm (FA) in multimodal optimization and concluded that the firefly algorithm can outperform the Particle Swarm Optimization (PSO) algorithm when performing the optimization of test functions. Similar results were obtained by Pal et al. [23] for noisy nonlinear optimization problems. Fister et al. [24], studied the firefly algorithm technique in detail and concluded that FA has a fast convergence rate, can tackle multi model problems effectively, can be applied for solving common or global problems, but can also be applied for every problem domain.

In the proposed study, workpieces made of $\mathrm{Al} 5083$ reinforced with $\mathrm{B}_{4} \mathrm{C}$ composite were butt joined using two different coated tools to analyse the mechanical properties of the joint, such as tensile strength and hardness. A mathematical model was established for both tensile strength and hardness for both tools and the fitness of the model was verified by means of ANOVA.

The influence of input parameters on the output response was also studied along with the condition of the tool after welding. The firefly algorithm was used to perform the multi objective optimization to obtain the best results.

\section{Experimental Approach}

For conducting the FSW experiments, preparation of workpieces, machining of tool, and selection of process parameters and their levels were important tasks to be done properly. The details of the aforementioned things are given in the following subdivisions. 

by Firefly Algorithm during the Friction Stir Welding of Metal Matrix Composites

\subsection{Preparation of workpieces and the tool}

In the current research, a composite of $\mathrm{Al} 5083$ reinforced with 10 percentage of $\mathrm{B}_{4} \mathrm{C}$ was prepared using the stir casting method; it was subsequently sliced in to plates of $100 \mathrm{~mm} \times 50 \mathrm{~mm} \times 6 \mathrm{~mm}$ using the wire Electrical Discharge Machining (EDM) process. To facilitate the process of joining, the rotating tool made of D3 tool steel was machined as a square pin profile with sides of $4 \mathrm{~mm}$ and pin length of $5.7 \mathrm{~mm}$. The diameter of the shoulder was maintained at $19.5 \mathrm{~mm}$. Wear of the tool due to the contact with the reinforcement is a big issue when trying to join composite materials. Two different tools were machined; they had the same size but one tool was coated with titanium nitride (TiN) and the other one with Diamond Like Carbon (DLC) on the tool pin and the shoulder portion. The machined tools before and after coating together with the coating characteristics are shown in Figure 3.

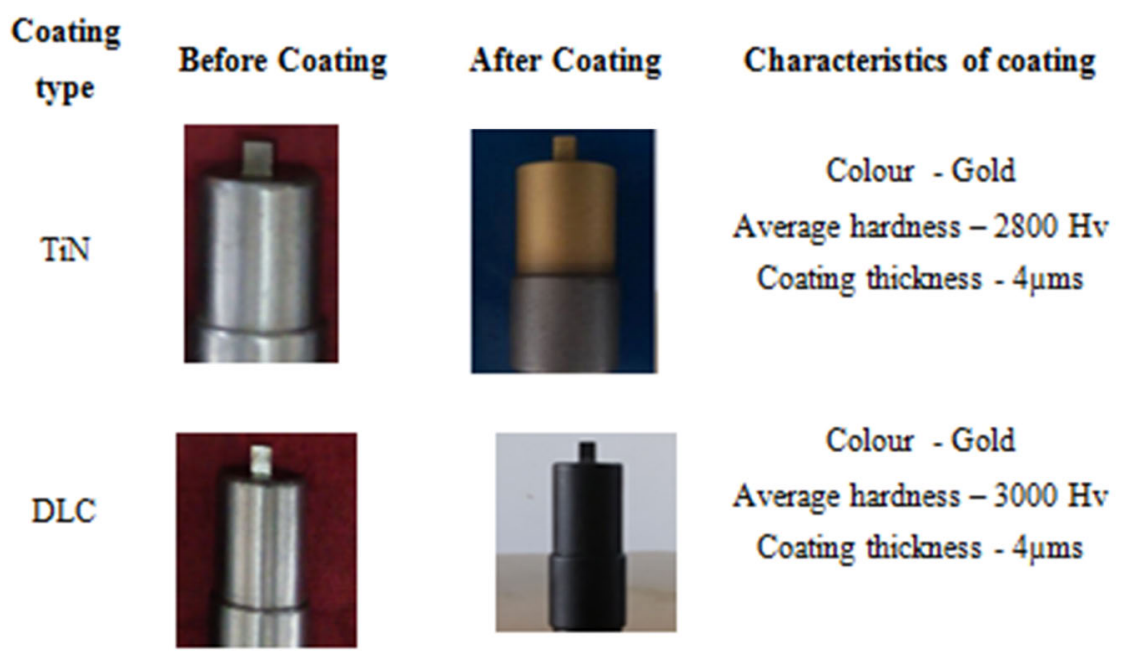

Fig. 3 Tools with coating characteristics

\subsection{Selection of process parameters}

FSW is a complex process, in which the quality of the weld is affected by many factors which are grouped into three main categories; tool related factors, machine related factors, and other supporting factors. In the present study, the machine related factors, such as the tool rotational speed, traverse feed, and axial force, were taken in three levels and the two tools with different coatings could be taken as parameters by keeping the remaining parameters untouched. The process parameters and their three levels are given in Table 1.

Table 1 Process parameters and their levels

\begin{tabular}{|c|c|c|c|c|c|c|}
\hline Specimen No & Welding parameter & Symbol & Unit & Level 1 & Level 2 & Level 3 \\
\hline 1 & Tool revolving speed & $\mathrm{P}$ & $\mathrm{Rpm}$ & 1200 & 1500 & 1800 \\
\hline 2 & Welding speed & $\mathrm{Q}$ & $\mathrm{mm} / \mathrm{min}$ & 20 & 40 & 60 \\
\hline 3 & Vertical plunge force & $\mathrm{R}$ & $\mathrm{KN}$ & 6 & 7 & 8 \\
\hline
\end{tabular}

\subsection{Experiments}

Experiments were planned according to the, Box-Behnken design which is a kind of response surface methodology (RSM), a mathematical technique very useful for modelling and analysing, and for optimizing the output response which is influenced by several variables. (Box Bhenken 2). A 15 run Box Behnken design was chosen with three factors and three levels, including three replicates at the centre point used for developing the model and for optimization. The experiments were conducted for both the TiN coated tool and the DLC 
coated tool. A total of 30 experiments were conducted to analyse mechanical properties and to develop a mathematical model. The welded joints were prepared using a CNC friction stir welding machine which is shown in Fig 4. Figure 5 shows some welded specimens.

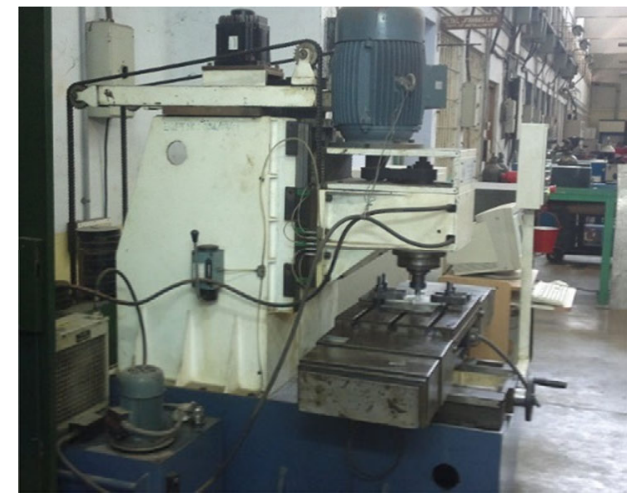

Fig. 4 FSW machine

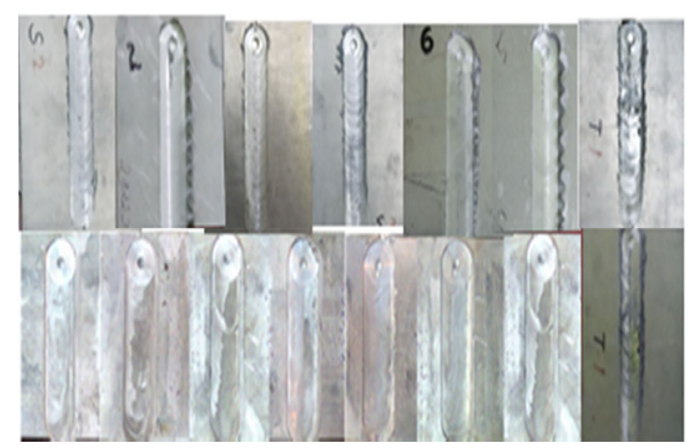

Fig. 5 Welded specimens

\subsection{Experimental results}

In order to examine the mechanical properties of the prepared weldments, they were cut into dog bone shape in the transverse direction, as per specifications given in the ASTM E- 8 standard, and then tested in a universal testing machine (UTM). The standard dimensions of the tensile specimen are shown in Fig 5. The tensile test specimens were cut using wire EDM and some specimens are shown in Fig 6. A total of three samples were prepared from each specimen to obtain the average values.

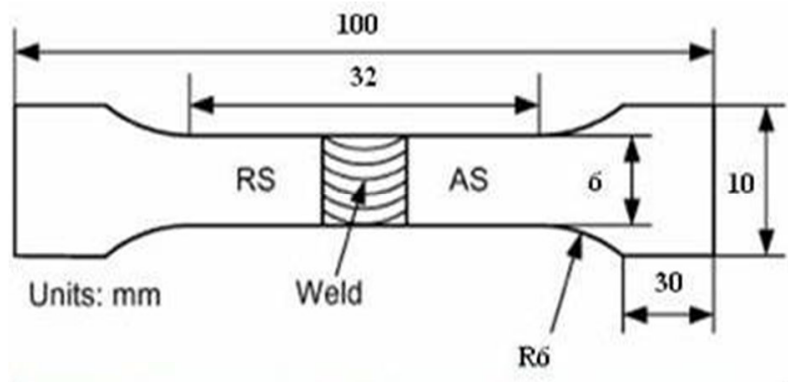

Fig. 6 Dimensions of tensile specimens

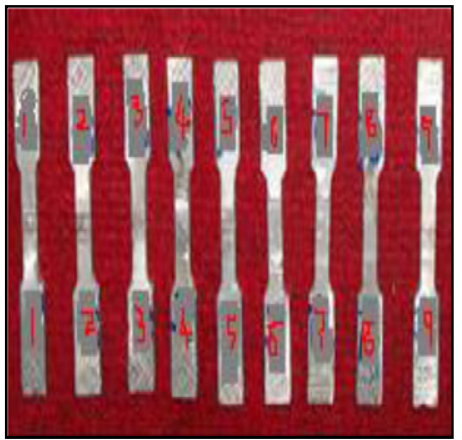

Fig. 7 Samples of tensile test specimens

The welded specimens were polished using conventional methods and hardness values were measured by the Vickers micro hardness method with a HV 0.5 load at different locations along the joint line to obtain the knowledge about process parameters.

\section{Development of a Mathematical Model}

The tensile strength and hardness of the welded joint are influenced by the tool rotational speed, welding speed, and the axial force; the objective function was to maximize the ultimate tensile strength (UTS) and hardness.

$$
\text { Maximize UTS and hardness }=\mathrm{fn}(P, Q, R)
$$

where UTS and hardness were the considered output responses, $P, Q$, and $R$, are the spindle speed, the welding feed, and the axial force, respectively. Generally response surface methodology is a kind of effective method for optimizing the process conditions and determining the influence of various factors on the output response. The version 12.0 of DESIGN EXPERT was used to accomplish the response surface methodology. 

by Firefly Algorithm during the Friction Stir Welding of Metal Matrix Composites

A mathematical model for predicting the tensile strength and hardness of the welded joint was developed for both the TiN coated and DLC coated tools. The regression equations in the actual form for tensile strength and hardness are given below in Equations 2 and 3, respectively, for the TiN coated tool, and in Equation 4 and 5, respectively, for the DLC coated tools.

Maximize UTS ' $\mathrm{Z1}$ ' $=111.54792+0.066244 \mathrm{P}-0.321021 \mathrm{Q}-5.55458 \mathrm{R}+0.000048 \mathrm{PQ}$

$+0.004083 \mathrm{PR}+0.101875 \mathrm{QR}-0.000032 \mathrm{P}^{2}-0.005093 \mathrm{Q}^{2}-0.37208 \mathrm{R}^{2}$

Maximize Hardness ' $\mathrm{Z} 2{ }^{\prime}=112.88583+0.051772 \mathrm{P}-0.349167 \mathrm{Q}-13.14417 \mathrm{R}-0.0001000$

PQ - 0.004292 PR +0.052375 QR - 6.11574 E-06 $\mathrm{P}^{2}+0.000786 \mathrm{Q}^{2}+1.28958 \mathrm{R}^{2}$

Maximize UTS' $\mathrm{Z3}^{\prime}=-41.82958+0.103828 \mathrm{P}-0.141771 \mathrm{Q}+26.00792 \mathrm{R}-0.000037 \mathrm{PQ}$ $-0.004125 \mathrm{PR}+0.0057250 \mathrm{QR}-0.000024 \mathrm{P}^{2}-0.002733 \mathrm{Q}^{2}-1.48833 \mathrm{R}^{2}$

Maximize Hardness ' $\mathrm{Z} 4$ ' $=73.61833+0.038951 \mathrm{P}-0.010917 \mathrm{Q}-1.31292 \mathrm{R}-0.000125$ $\mathrm{PQ}-0.002683 \mathrm{PR}+0.072375 \mathrm{QR}-4.99074 \mathrm{E}-06 \mathrm{P}^{2}-0.003392 \mathrm{Q}^{2}+0.205833 \mathrm{R}^{2}$

The fitness of the model was examined using a technique called the Analysis of Variance (ANOVA). It was observed from the literature that the $F$ value greater than 4 is anticipated for the model to be adequate; the developed models have the $\mathrm{F}$ value greater than 4 and they were significant. The results of the ANOVA test are shown in Table 2.

Table 2 Results of the ANOVA test

\begin{tabular}{|c|c|c|c|c|c|c|c|c|c|c|c|}
\hline \multirow{2}{*}{$\begin{array}{l}\text { Tool } \\
\text { Coating }\end{array}$} & \multirow{2}{*}{$\begin{array}{l}\text { Output } \\
\text { response }\end{array}$} & \multicolumn{2}{|c|}{ Sum of squares } & \multicolumn{2}{|c|}{ Mean squares } & \multicolumn{2}{|c|}{ Degrees of freedom } & \multirow{2}{*}{$\begin{array}{l}\text { F - } \\
\text { Ratio }\end{array}$} & \multirow{2}{*}{$\begin{array}{c}\mathrm{R}^{2} \\
\text { Value }\end{array}$} & \multirow{2}{*}{$\begin{array}{c}\text { Adjusted } \\
\mathrm{R}^{2}\end{array}$} & \multirow{2}{*}{ Remarks } \\
\hline & & Regression & Residual & Regression & Residual & Regression & Residual & & & & \\
\hline \multirow{2}{*}{ TiN } & UTS & 79.32 & 2.25 & 8.81 & 0.4496 & 9 & 5 & 19.60 & 97.24 & 92.28 & Significant \\
\hline & Hardness & 39.09 & 1.27 & 4.34 & 0.2550 & 9 & 5 & 17.04 & 96.84 & 91.16 & Significant \\
\hline \multirow{2}{*}{ DLC } & UTS & 52.35 & 0.8173 & 5.82 & 0.1635 & 9 & 5 & 35.58 & 98.46 & 95.70 & Significant \\
\hline & Hardness & 26.94 & 2.79 & 2.99 & 0.5572 & 9 & 5 & 5.37 & 90.63 & 73.75 & Significant \\
\hline
\end{tabular}

\section{Multi Objective Optimization by Firefly Algorithm}

In 2008, Xin -She Yang from Cambridge University was inspired by the flashing behaviour of fireflies and developed a metaheuristic algorithm known as firefly algorithm. Many continuous optimization problems are solved using the firefly algorithm. In general there are three idealized rules used by the firefly algorithm which are described in [25].

Regardless of their sex, two fireflies attract each other due to their unisexual nature.

For any two fireflies, their attraction depends on the brightness: a less bright firefly will be attracted towards a brighter one, and, as the distance between them increases, the attraction decreases.

The landscape of the objective function determines the brightness of the firefly [26]. In order to get the optimum combination of process parameters which satisfies both objectives, a combined objective function was formulated using the weighted sum method, by allocating equal weighting to both objectives [27]. The combined objective function for the TiN coated and the DLC coated tool is expressed in Equations (6) and (7), respectively.

$$
\begin{aligned}
& \text { Maximize } \mathrm{Z}(\mathrm{TiN})=\mathrm{W} 1 \times(\mathrm{Z} 1 / \mathrm{Z} 1 *)+\mathrm{W} 2 \times\left(\mathrm{Z} 2 / \mathrm{Z} 2^{*}\right) \\
& \text { Maximize } \mathrm{Z}(\mathrm{DLC})=\mathrm{W} 3 \times\left(\mathrm{Z} 3 / \mathrm{Z} 3^{*}\right)+\mathrm{W} 4 \times(\mathrm{Z} 4 / \mathrm{Z} 4 *)
\end{aligned}
$$


Figures 8 and 9 show the convergence graph of UTS and hardness, respectively, for TiN coated tool. From the graphs, it is observed that a maximum value of $135.628 \mathrm{MPa}$ is reached within 20 iterations and the value is stabilized thereafter for UTS optimization. While optimizing the Vickers hardness value, a maximum value of 103 (HV 0.5) was achieved within 10 iterations and thereafter the value was steady. The number of fireflies considered is 50 for both responses.

For the DLC coated tool, the convergence graphs for UTS and hardness are shown in Figures 10 and 11, respectively. A maximum value of $129.78 \mathrm{MPa}$ was reached with about 20 iterations for strength and a hardness value of 102.96 was obtained with less than 10 iterations.

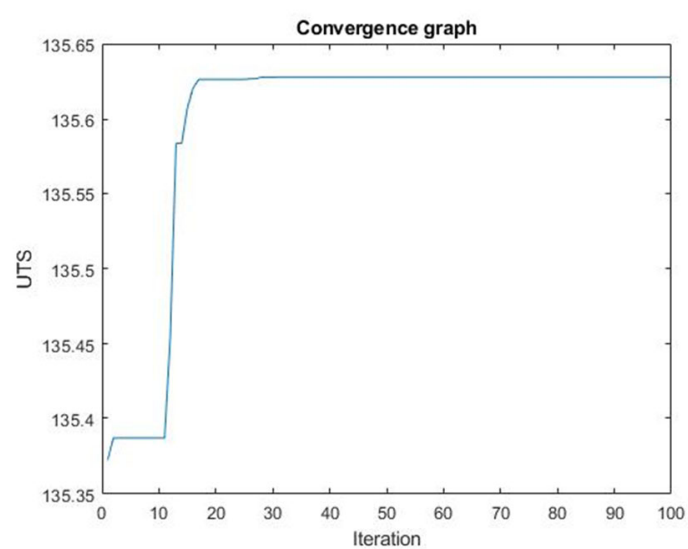

Fig. 8 Convergence graph of UTS for the TiN coated tool

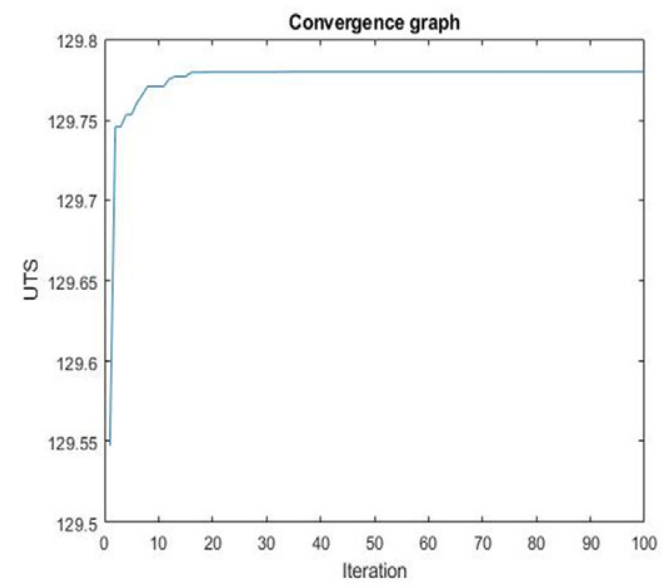

Fig. 10 Convergence graph of UTS for the DLC coated tool

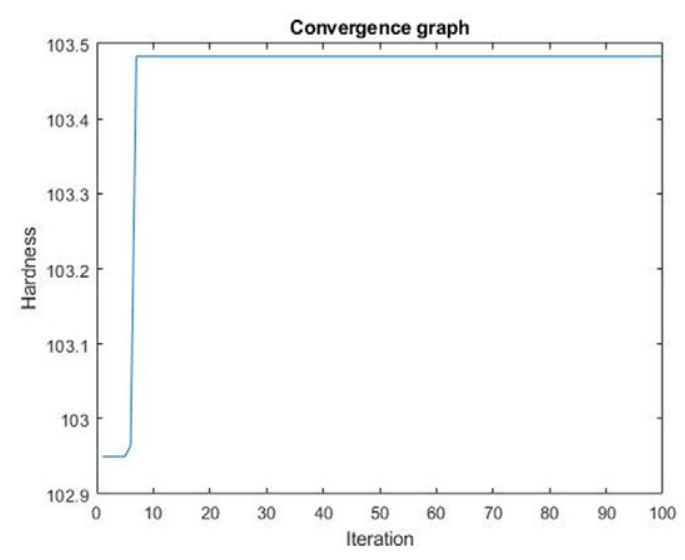

Fig. 9 Convergence graph of hardness for the TiN coated tool

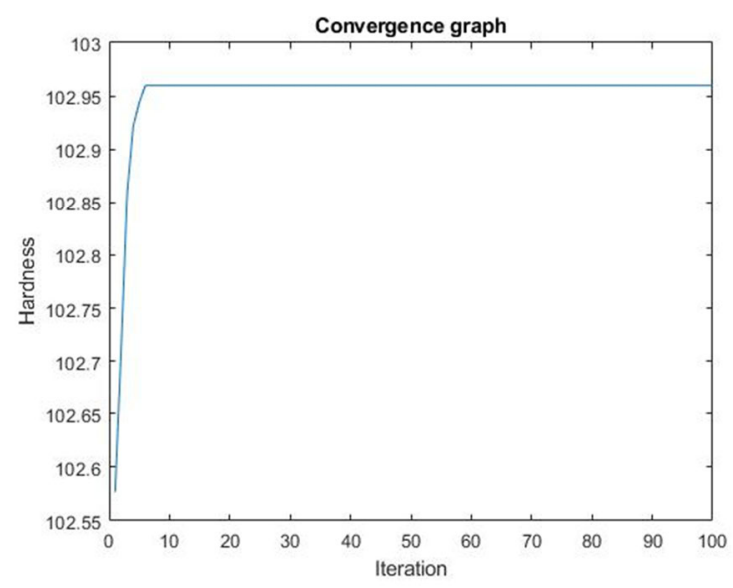

Fig. 11 Convergence graph of hardness for the DLC coated tool

$\mathrm{Z} 1 *$ and $\mathrm{Z} 2 *$ are the maximum optimized values obtained by solving Equations 2 and 3 , respectively, for the TiN coated tool. Similarly, for the DLC coated tools, Z3* and Z4*, the maximum optimized values, were obtained from Equations 4 and 5, respectively. The firefly algorithm was done using the MATLAB R2018a version of software to obtain the optimized values of tensile strength and hardness for the TiN coated and DLC coated tools. For the TiN coated tool, the optimized process parameters for obtaining both better tensile strength and hardness were as follows: spindle speed of $1540 \mathrm{rpm}$, welding speed of $20 \mathrm{~mm} / \mathrm{min}$, and axial force of $6 \mathrm{KN}$; maximum tensile strength of $133.92 \mathrm{MPa}$ and hardness of 102.54, respectively, were obtained with these parameters. To obtain the optimized results, the population strength and the number of iterations was fixed at 100. The convergence graph for 

by Firefly Algorithm during the Friction Stir Welding of Metal Matrix Composites

the individual and combined responses is shown in Fig. 12, from which it was clear that the maximum values were obtained in a minimum number of iterations.

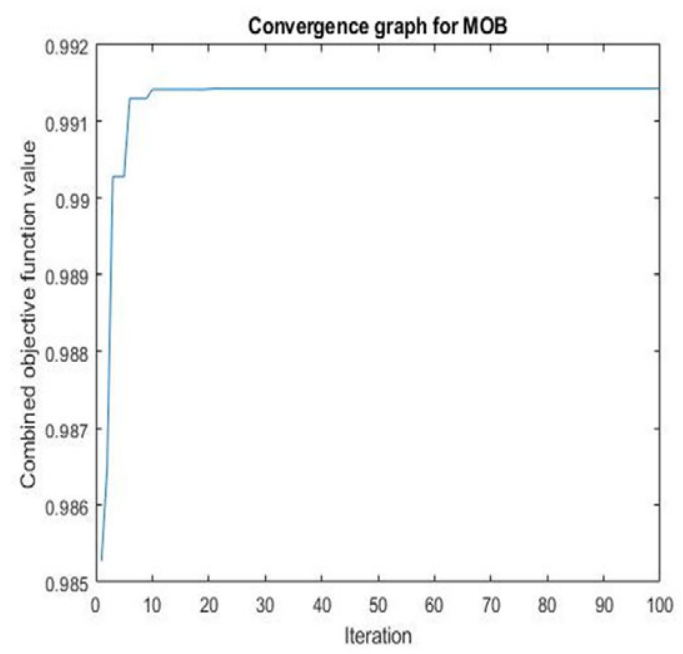

Fig. 12 Convergence graph of the combined response for the TiN coated tool

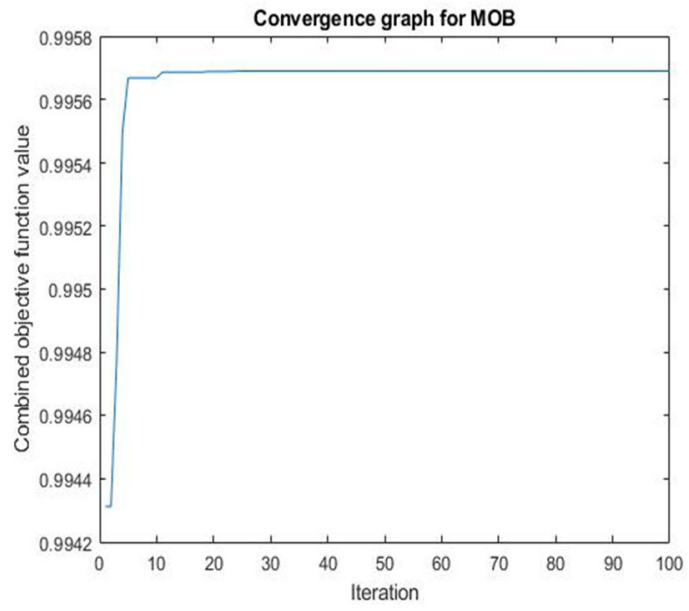

Fig. 13 Convergence graph of the combined response for the DLC coated tool

For the DLC coated tool, the values of spindle speed of $1360 \mathrm{rpm}$, welding speed of 55 $\mathrm{mm} / \mathrm{min}$, and axial force of $8 \mathrm{KN}$ gave the combined maximum values for tensile strength and hardness as $129.26 \mathrm{MPa}$ and 102.47 respectively. Figure 13 shows the convergence graph for the DLC coated tool.

\section{Impact of Process Parameters}

The effect of process parameters, such as the tool revolving speed, welding speed and vertical plunge force, on mechanical properties such as ultimate tensile strength and micro hardness are discussed in the following subsections.

\subsection{Impact of tool revolving speed}

The effect of revolving speed on both ultimate tensile strength and hardness follows the same trend. Figures 14 and 15 show the effect of speed on UTS and hardness respectively. An increase in the revolving speed increases the strength and the hardness of the joint up to a certain value, because by increasing the spindle speed, friction is increased and in turn the heat input, which leads to an improvement in properties. On the other hand, by further increasing the speed, the mechanical properties are decreased due to a higher heat input, which results in slow cooling and formation of coarse grains.

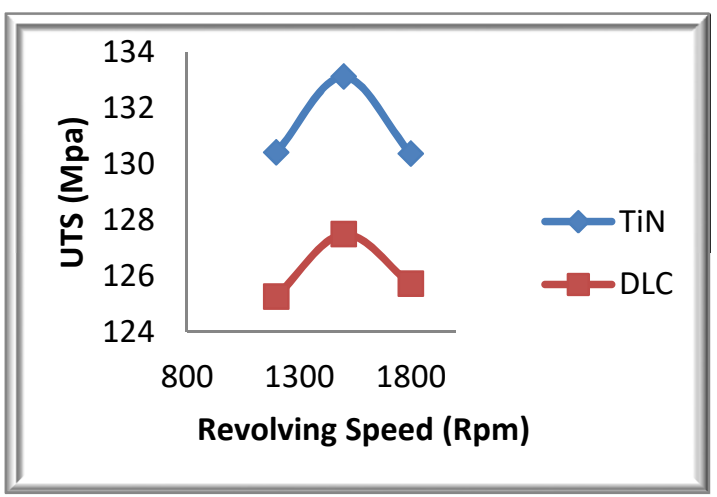

Fig. 14 Influence of revolving speed on UTS

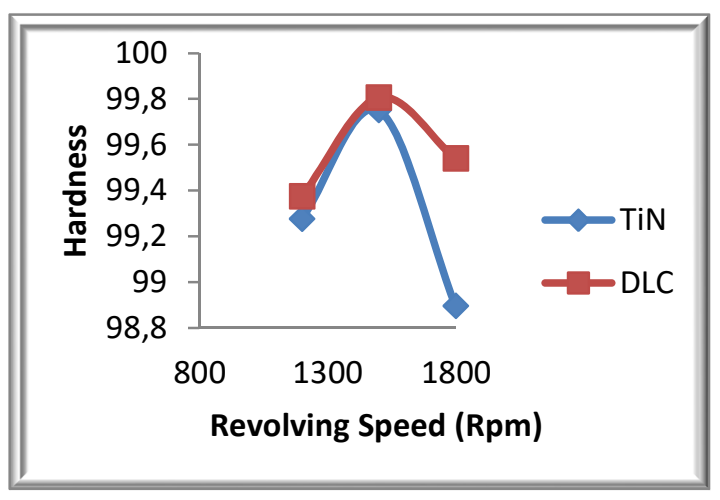

Fig. 15 Influence of revolving speed on hardness 


\subsection{Impact of welding speed}

The welding speed is the rate at which the tool is moved along the joint line. An increase in the welding speed increases the tensile strength of the joint up to a certain value: a further increase in feed, decreases the strength. This is because at higher welding speeds, the tool moves at a faster rate, which leads to an insufficient heat input and reduces the strength. The hardness values of DLC coated tools follow a similar trend to that of the ultimate tensile strength. In contrast, an increase in the welding speed decreases steadily the hardness values of the TiN coated tool. Figures 16 and 17 show the effect of welding speed on UTS and hardness, respectively.

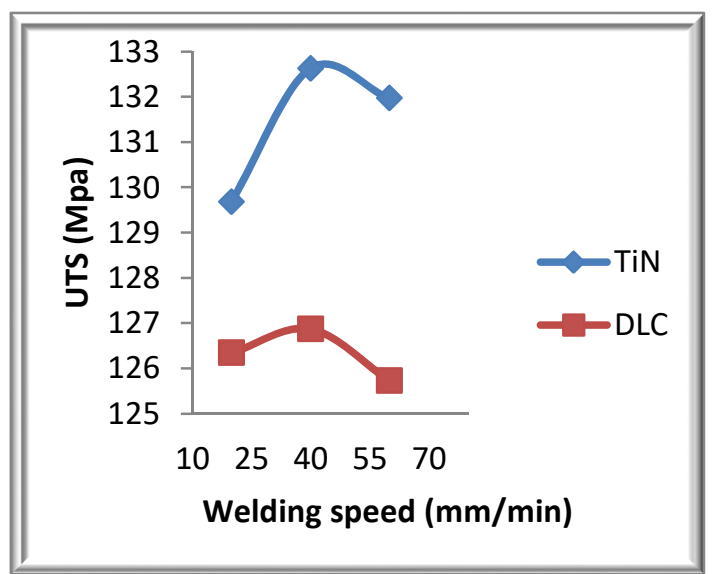

Fig. 16 Influence of welding speed on UTS

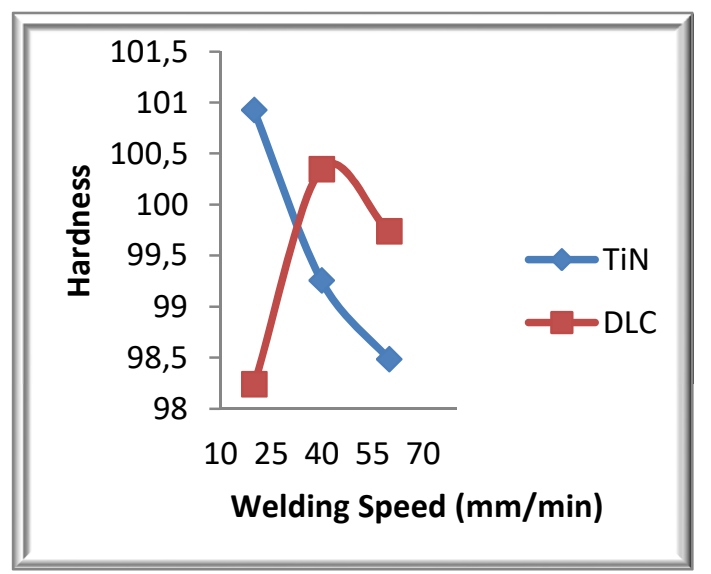

Fig. 17 Influence of welding speed on hardness

\subsection{Impact of vertical plunge force}

Figures 18 and 19 show the effect of axial force on output responses. An increase in the axial force value decreases the ultimate tensile strength and hardness values of the TiN coated tool due to the expulsion of material away from the stir zone. On the other hand, an increase in the axial force value increases the strength and hardness values of the DLC coated tool because of proper consolidation.

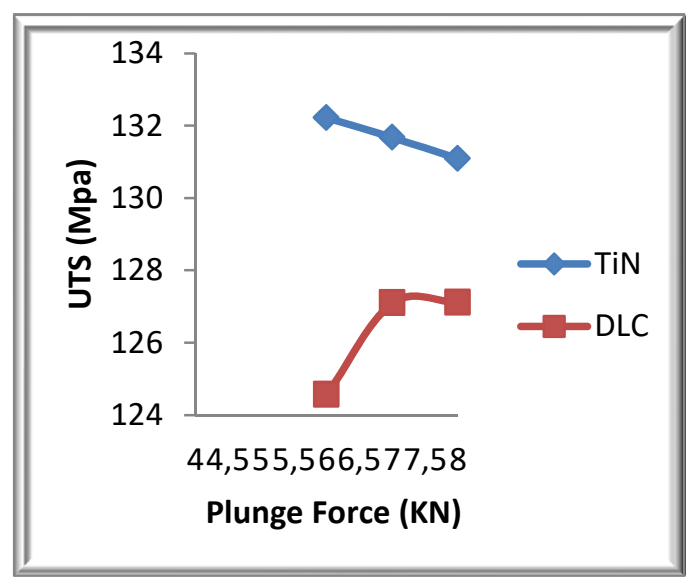

Fig. 18 Influence of plunge force on UTS

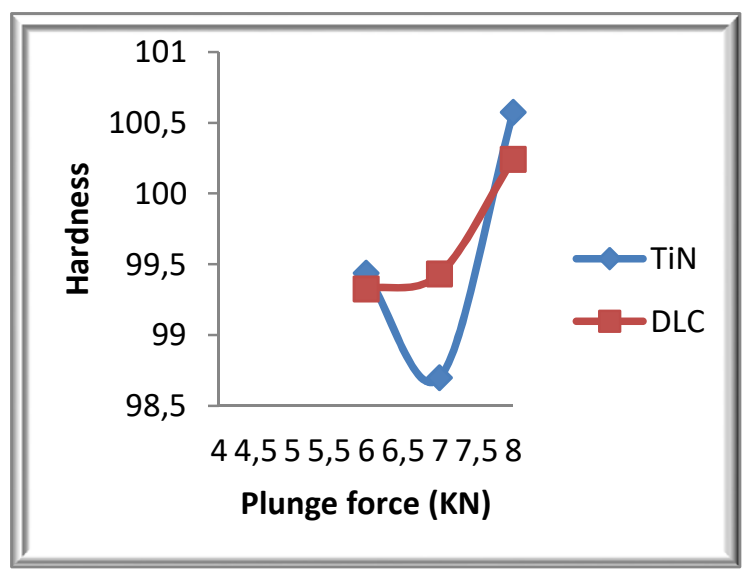

Fig. 19 Influence of Plunge force on hardness

\section{Conclusion}

Aluminium metal matrix composites were joined by using two differently coated tools. Based on the results obtained from the experimental work, the following conclusions were made.

- The FSW process can be applied to join 10\% $\mathrm{B}_{4} \mathrm{C}$ reinforced $\mathrm{Al} 5083$ composites effectively using the TiN and DLC coated tools. 
- The combined optimized process parameters were obtained using the firefly algorithm.

- For the TiN coated tool, the optimized process parameters for obtaining better tensile strength and hardness were: spindle speed of $1540 \mathrm{rpm}$, a welding speed of $20 \mathrm{~mm} / \mathrm{min}$, and an axial force of $6 \mathrm{KN}$ : thus maximum tensile strength of 133.92 $\mathrm{MPa}$ and hardness of 102.54 were obtained.

- For the DLC coated tool, the values of spindle speed, welding speed and axial force were $1360 \mathrm{rpm}, 55 \mathrm{~mm} / \mathrm{min}$, and $8 \mathrm{KN}$, respectively: thus maximum values of tensile strength of $129.26 \mathrm{MPa}$ and hardness of 102.47 were obtained.

- The TiN coated tool produced better ultimate tensile strength and hardness values than the DLC coated tool.

\section{REFERENCES}

[1] https://www.machinedesign.com/materials/future-metal-matrix-composites TomBarrett, ( accessed on June 02, 2017)

[2] Tracie Prater, "Friction stir welding of Metal Matrix Composites for use in aerospace structures", Acta Astronautica, 2014, Vol.93, pp.366-373. https://doi.org/10.1016/j.actaastro.2013.07.023

[3] Sundaravel Vijayan, R. Raju \& S. R. K Rao, Multiobjective Optimization of Friction Stir Welding Process Parameters on Aluminum Alloy AA 5083 Using Taguchi-Based Grey Relation Analysis, Materials and Manufacturing Processe, 2010, 25:11, pp 1206-1212. https://doi.org/10.1080/10426910903536782

[4] Nami. H, Adgi. H, Sharifitabar. M, Shamabadi. H, "Microstructure and mechanical properties of friction stir welded Al/Mg2Si metal matrix cast composite", Materials and Design, 2011, Vol. 32, pp. 976-983. https://doi.org/10.1016/j.matdes.2010.07.008

[5] Dinaharan. I, Murugan. N, Automation of friction stir welding process to join aluminium matrix composites by optimization, Procedia Engineering, 2012, Vol. 38, pp. $105-110$. https://doi.org/10.1016/j.proeng.2012.06.015

[6] Kalaiselvan.K, \& Murugan.N, Optimizations of friction stir welding process parameters for the welding of Al-B4C composite plates using generalized reduced gradient method, Procedia Engineering, 2012 Vol 38, pp 49 -55. https://doi.org/10.1016/j.proeng.2012.06.008

[7] Adel Mahmood Hassan, Mohammed Almomani, Tarek Qasim \& Ahmed Ghaithan, Effect of Processing Parameters on Friction Stir Welded Aluminum Matrix Composites Wear Behavior, Materials and Manufacturing Processes, 2012, 27:12, 1419-1423. https://doi.org/10.1080/10426914.2012.700156

[8] Mohsen Bahrami, Mohammad Kazem Besharati Givi, Kamran Dehghani, Nader Parvin, "On the role of pin geometry in microstructure and mechanical properties of AA7075/SiC nano-composite fabricated by friction stir welding technique", Materials and Design, 2014,Vol 53, pp. 519-527. https://doi.org/10.1016/j.matdes.2013.07.049

[9] C.Ravindiran, P.PravinKumar, L.Vinoth, "A Characteristics study of Aluminum Metal Matrix in Friction Stir Welding Process", south Asian Journal of Engineering and Technology, 2016, Vol 2, No. 22, 187- 205.

[10] V. K. Parikh, A. D. Badgujar \& N. D. Ghetiya, "Joining of metal matrix composites using Friction stir welding: a review, Materials and Manufacturing Processes, 2018. https://doi.org/10.1080/10426914.2018.1532094

[11] D.Jayabalakrishnan, M.Balasubramanian, "Eccentric - Weave FSW between Cu and AA 6061 -T6 with reinforced Graphene nanoparticles", Materials and Manufacturing Processes, 2017. https://doi.org/10.1080/10426914.2017.1339323

[12] M.Jayaraman, R.Sivasubramanian, V.Balasubramanian, "Establishing relationship between the base metal properties and friction stir welding process parameters of cast aluminium alloys" Materials \& Design, 2010, Vol.31, Issue 9, pp 4567 - 4576. https://doi.org/10.1016/j.matdes.2010.03.040

[13] Y.G.Kim, H.Fujii, T.Tsumuru, T.Komazaki, K.Nakata, “ Three defect types in friction stir welding of aluminum die casting alloy”, Materials Science and Engineering A, 2006, 415, pp 250 - 254. https://doi.org/10.1016/j.msea.2005.09.072

[14] D.Klobcar, J.Tusek, A.Smolej, S.Simoncic, "Parametric study of FSSW of aluminium alloy 5754 using a pinless tool", Weld world, 2015, 59: pp 269 - 281. https://doi.org/10.1007/s40194-014-0208-X 
[15] E. Shankar, S. Balasivanandha Prabu, T. Sampath Kumar, M. R. Stalin John, "Investigation of TiAlN coated roller burnishing on Al-(B4C)p MMC workpiece material, Materials and Manufacturing Processes, 2018. https://doi.org/10.1080/10426914.2018.1453160

[16] H. Horn: Friction Stir Welding of Aluminium Foam Materials, Welding in the World-London (2001).

[17] M.Busic, Z.Kozuh, D.Klobcar, I.Samardzic, "Friction stir welding (FSW) of aluminium foam sandwich panel”, Metalurgija, 2016, 55, 3, pp 473 - 476.

[18] Yoshihiko Hangai, Hiroto Kamada, Takao Utsunomiya, Soichiro Kitahara, Osamu Kuwazuru, Nobuhiro Yoshikawa, "Aluminum alloy foam core sandwich panels fabricated from die casting aluminum alloy by friction stir weldimg routr”, Journal of materials processing technology, 2014, Vol 214, issue 9, pp 1928 - 1934. https://doi.org/10.1016/j.jmatprotec.2014.04.010

[19] Hrishikesh Das, Mounarik Mondal, Sung-Tae Hong, Doo-Man Chun, Heung Nam Han, “Joining and Fabrication of Metal Matrix Composites by Friction Stir Welding / Processing, International Journal of Precision Engineering and Manufacturing Green Technology, 2018, Vol 5, No1, 151 -172. https://doi.org/10.1007/s40684-018-0016-7

[20] Prabhu Subramanya, Murthy Amar, Shettigar Arun, Herbert Mervin, Rao Shrikantha, "Friction stir welding of Aluminium matrix composites - A Review”, ATEC Web of Conferences, 2018144. https://doi.org/10.1051/matecconf/201714403002

[21] M.Sadeghi Ghogheri, M.Kasiri Asgarani, K.Amini, "Friction stir welding of dissimilar joints between commercially pure titanium ally and 7075 aluminium alloy" Transanctions of FAMENA, XLI -1 2017. https://doi.org/10.21278/tof.41107

[22] G.Beni, J.Wang, Swarm Intelligence in: Proceedingd of NATO Advanced workshop on Robotics and Biological systems, Tuscany, Italy, 1989, pp $26-30$.

[23] Yang, X.S. "Nature inspired metaheuristic algorithm”, in Firefly Algorithm, 2nd ed., pp.81-89, Luniver Press, 2010, University of Cambridge, UK.

[24] Pal, S., Rai, C.S. and Singh, A. "Comparative study of firefly algorithm and particle swarm optimization for noisy non-linear optimization problems", International Journal of Intelligent Systems and Applications, 2012, Vol. 10, No. 10, pp.50-57. https://doi.org/10.5815/ijisa.2012.10.06

[25] Fister, I., Fister Jr., I., Yang, X.S. and Brest, J. “A comprehensive review of firefly algorithms”, Swarm and Evolutionary Computation, 2013, Vol. 13, pp.34-46. https://doi.org/10.1016/j.swevo.2013.06.001

[26] Xin-She Yang, Xingshi He, "Firefly Algorithm: Recent Advances and Applications", 2013, arXiv: 1308.3898v1 [math.OC].

[27] Azlan Mohd Zain, Noorfe Mustaffa, Amimudin Udin, "Firefly Algorithm for Optimization Problem", Applied Mechanics and Materials, 2013, Vol. 421, 512-517.

https://doi.org/10.4028/www.scientific.net/amm.421.512

$\begin{array}{lll}\text { Submitted: } \quad 08.5 .2020 & \text { C. Devanathan, Assistant Professor } \\ & & \text { Department of Mechanical Engineering, } \\ \text { Accepted: } & 11.01 .2021 & \text { Rajalakshmi Engineering College, } \\ & \text { Chennai, Tamil Nadu, India } \\ & \text { A. SureshBabu, Associate Professor } \\ & \text { Department of Manufacturing } \\ & \text { Engineering, Anna University, Chennai, } \\ & \text { Tamil Nadu, India }\end{array}$

